\title{
Transferring the financial risks of pharmaceutical benefits from a large health care provider in Argentina to a consortium of pharmaceutical companies
}

\author{
Juan C. Cervellino, ${ }^{1}$ Sandra B. Corazza, ${ }^{2}$ Inés M. I. Bignone, ${ }^{2}$ \\ M. Diana Fligman, ${ }^{2}$ Silvana Figueroa, ${ }^{3}$ Rubén Roldán, ${ }^{4}$ Pablo Morici, ${ }^{5}$ \\ and Roberto A. Diez ${ }^{2}$
}

ABSTRACT Objective. The National Institute of Social Services for Retirees and Pensioners (NISSRP) is a nationwide health care financing agency and service provider in Argentina. Among its services, the NISSRP provides outpatient drug coverage to more than 3.3 million beneficiaries, mainly senior citizens and disabled persons. In 1997, to help cope with its rising costs, the NISSRP agreed to transfer the risk for the cost of outpatient medications and cancer-treatment drugs to a consortium of pharmaceutical companies in exchange for a fixed monthly payment. The objective of this study was to determine the impact that this new approach had on three things: (1) the level of expenditures for the medicines that were included in the agreement, (2) the pattern of nonrational prescribing for NISSRP beneficiaries, and (3) this pattern's relationship with macroeconomic variables and the pattern of prescribing for Argentina as a whole. Methods. We compared outpatient-medicine consumption in 1999 with consumption before the agreement went into effect.

Results. The actual amount that NISSRP beneficiaries spent out-of-pocket climbed from US\$ 336.13 million in 1996 to US\$ 473.36 million in 1999, an increase of almost 41\%. The nominal amount "spent" by the NISSRP in 1999 was US\$ 601.11 million, versus a real amount of US\$ 374.75 million in 1996, an "increase" of 60\% (that increase for the NISSRP was only theoretical since the agreement specified the fixed monthly amount that the NISSRP would have to pay to the pharmaceutical consortium). In contrast with the increased real spending by NISSRP beneficiaries, Argentina's economy remained stable over the assessed period, with the consumer price index even falling by $0.8 \%$. We found high levels of nonrational drug use in the NISSRP system in both 1996 and 1999, indicating a serious ongoing problem. Conclusions. An agreement with pharmaceutical companies, like the one we have described, might add an element of financial predictability for institutions such as the NISSRP. However, such an agreement can easily result in an increased economic burden for health care

\footnotetext{
1 National Institute of Social Services for Retirees and Pensioners, Department of Medicines, Buenos Aires, Argentina.

2 University of Buenos Aires, School of Medicine, Department of Pharmacology, Buenos Aires, Argentina. Send correspondence to: Roberto A. Diez,

Department of Pharmacology, School of Medicine, University of Buenos Aires, Paraguay 2155, Piso 16, 1121 Buenos Aires, Argentina; telephone/fax: (5411) 4964-0505; e-mail: rdiez@fmed.uba.ar

3 University of Buenos Aires, School of Medicine, Informatics Department, Buenos Aires, Argentina.

4 National Institute of Social Services for Retirees and Pensioners, Economic Affairs Office, Buenos Aires, Argentina.

5 National Institute of Social Services for Retirees and Pensioners, Office of the Sub-Intervenor, Buenos Aires, Argentina.
} 
beneficiaries, and without any improvement in the services that they receive. This type of agreement requires extensive mechanisms for control, follow-up, and updating, and it also risks making nonrational drug prescribing the accepted rule. While perhaps feasible, the requirements for this kind of agreement are actually very difficult to put into place, requiring additional efforts from institutions such as the NISSRP.

Key words Health care economics and organizations, drug utilization, prescription drugs, national health programs, Argentina.

Rising pharmaceutical costs are a difficult problem for most health systems, both in developed and developing countries. Between 1987 and 1999, expenditures for prescription medicines increased yearly by $12.6 \%$ in the United States of America (1). In Argentina, the corresponding yearly increase between 1991 and 1998 was slightly over $10 \%$ (2).

The National Institute of Social Services for Retirees and Pensioners (NISSRP), (Instituto Nacional de Servicios Sociales para Jubilados y Pensionados) is the single largest health system in Argentina. In 1997 the NISSRP reached an agreement with a consortium of pharmaceutical companies to transfer to them the risk of increasing pharmaceutical costs. Essentially, drug companies were to receive a fixed monthly amount to provide pharmaceutical benefits to all outpatients affiliated with the NISSRP. Even drugs required for cancer treatment were included, along with ambulatory hemodialysis products.

The rationale for this new approach probably included the need for the NISSRP to cope with rising costs and the awareness that drug companies were economically the most powerful segment among pharmaceutical service providers. As far as we co-authors know, this transfer of economic risk to the pharmaceutical companies in Argentina is the first experience with this approach in either a developed or developing country. This makes the Argentine experiment a leading case for testing this approach.

Why did the pharmaceutical companies accept the agreement? The answer is not evident, but in part it probably involved the long-term record of the
NISSRP as a poor payer. For instance, by the year 1996, the NISSRP owed some US\$ 1200 million to providers of medical and clinical laboratory services. Another reason may have been the risk of default and collapse of the pharmaceuticals system since the NISSRP is the single largest component of the pharmaceuticals market in Argentina. Still another possible factor was the increased participation of corporate interests in the decision-making of the NISSRP that came with the agreement. For the first time in the NISSRP's history, the agreement required that for new products to be included among those available to NISSRP beneficiaries, the pharmaceutical consortium had to provide its consent.

This report looks at the impact of the new system and compares the costs and prescribing patterns during 1999 with the costs and prescribing patterns before the agreement was put into effect. In July 2000, the agreement was renewed after several months of negotiation. The results presented in this article are only for the period that ended in December 1999. We have not looked at what has happened with the NISSRP system or the agreement in the years since 1999, when economic conditions in Argentina have changed very dramatically, e.g., in 2001 and 2002.

\section{BACKGROUND}

\section{Argentina}

One of the Southern Cone nations of Latin America, Argentina has a federal government structure, and it has an area of $2791810 \mathrm{~km}^{2}$. According to the Argentine National Institute of Statis- tics and Census (3), in 1999 the country had 36600000 inhabitants, with a high concentration $(89.3 \%$ of the population) in several urban areas. In that same year, average life expectancy at birth was 75.05 years (71.67 years for men and 78.71 for women), and $8.8 \%$ of the population was 65 years old or older. In 1991 almost 20\% of the population was classified as "poor," that is, lacking such essential services as proper housing and school attendance by their children. In 1999, the proportion of people classified as poor ranged from $8.1 \%$ in the city of Buenos Aires to $39.1 \%$ in the province of Formosa.

\section{Argentina's health system}

The health system of Argentina is highly fragmented and poorly coordinated (4). Three main sectors provide funding for health care: the public sector (national, provincial, and city governments), trade unions (through obras sociales, which are organizations created and/or operated by the unions under special legislation), and the private sector (mainly health maintenance organizations). There is much overlap among the different sectors. For example, beneficiaries from the private sector and trade union organizations can use both the services owned by or contracted for them and the public hospitals (usually with no payment).

\section{The macroeconomic context}

In the late 1980s, Argentina suffered a significant inflationary process (3). Between 1991 and 1999, the Argentine 
economy changed significantly. This was due to several macroeconomic decisions, including the use of a fixed exchange rate (1 Argentine peso $=$ US\$ 1.00), a federal law allowing the free exchange between pesos and dollars, and, since 1992, the abolition of price regulations for pharmaceuticals and other goods. There was also a progressive privatization of public companies and a substantial decrease in the inflation rate. In the second half of the 1990s, the economy was generally stable, with virtually no inflation; between May 1997 and December 1999, the inflation rate (the change in the consumer price index) was $-0.8 \%$. The gross domestic product was US\$ 272150 million in 1996 and US\$ 282769 million in 1999 (both stated as then-current values).

\section{The National Institute of Social Services for Retirees and Pensioners}

An agency of the Government of Argentina, the NISSRP was created in 1971 with the aim of providing health services for retirees and their dependents as well as for people with any kind of severe disability. The NISSRP central headquarters is in Buenos Aires, where its Department of Medicines is also located. As will be described in more detail below, the main duty of the Department of Medicines is to define treatment recommendations for uncommon clinical situations and to assess so-called "special exception" applications for providing NISSRP beneficiaries with pharmaceutical products for free (without any copayment). The NISSRP also has 33 district offices (delegaciones) in the various provinces. The NISSRP expenditures for fiscal year 1996 were US\$ 2767 million, including the salaries of its employees. The figure for 1999 was US\$ 2667 million. (The fiscal year in Argentina begins in January and ends in December.) The funding for the NISSRP comes from a portion of the salaries of active workers, the salaries of retirees, and the pensions of pensioners as well as from contributions from employers.
The NISSRP program of drug benefits is nationwide and provides different levels of coverage according to the kind of medicine prescribed: $100 \%$ for drugs for acute conditions that, if not provided, can result in death or severe complications, such as insulin or antiepileptics; $80 \%$ for medicines intended for chronic disorders, such as the main drugs for hypertension (based on international consensus, e.g., atenolol); $50 \%$ for alternative drugs for chronic disorders or drugs for severe, acute disease (e.g., prazosin for hypertension or most antibiotics for acute infection); and 30\% for other prescriptions.

\section{The NISSRP population}

To become an NISSRP beneficiary, a person must be a retiree or a pensioner or the dependent of a beneficiary. Pensioners are a heterogeneous group, including people with a disability such as a physical or mental disorder, and war veterans. After updating the database of beneficiaries, the Statistics Department of the NISSRP calculated that the number of beneficiaries (including all categories) in September 2000 was 3357 384; since then, this information has been periodically updated. Though the reason is unclear, during 1997-1999 the database of beneficiaries was not regularly updated by the NISSRP, resulting in duplicated affiliations and even inclusion of persons who had died. As a result of this failure, the true number of beneficiaries during that 1997-1999 period was and still is unknown. Most estimates that were done for NISSRP internal use calculated the number of beneficiaries to then be around 4000000 people, but those estimates are now considered to have been wrong.

In September 2000, the age distribution of the beneficiaries was: 150964 people who were 15 years old or younger, 602190 between 16 and 59 years old, and 2604230 who were 60 or older. By gender, 2158548 beneficiaries were female and 1198836 were male. Females begin to make up a majority of the beneficiaries around the age of 50 .

\section{The pharmaceutical industry in Argentina}

More than 200 pharmaceutical companies share the pharmaceutical market in Argentina. The size of the market in the 1990s was estimated at between US\$ 3500 and 6000 million, depending on the year and the source of the information (2). What is believed to be the best estimate comes from a marketing survey regularly performed by IMS HEALTH, a firm based in Westport, Connecticut, United States of Americas. These 200-plus pharmaceutical companies include both multinational corporations and domestic companies, and they are organized into three major industry associations. The existence of the three different associations partly reflects the divergent opinions and interests of the companies (e.g., multinational vs. domestic, large vs. small) concerning intellectual property and patent rights for pharmaceuticals. Argentine-owned companies hold slightly over half of the market. Despite their differences, the three associations together signed the agreement with the NISSRP.

\section{The agreement}

Around early 1997, the NISSRP began negotiations with the pharmaceutical associations on a possible agreement for pharmaceutical companies to provide, distribute, and dispense outpatient medications as well as drugs for cancer, throughout the country. An agreement was signed on 20 May 1997, to be effective as of June 1997. The three associations created an intermediate, nonprofit organization called the Business Collaboration Group (BCG) (Agrupamiento de Colaboración Empresaria, or ACE). The BCG was to receive a fixed monthly payment of US\$27.5 million and to use this money to pay for the pharmaceutical services corresponding to the NISSRP outpatient and cancer medications. The BCG signed additional agreements with the various organizations that represent pharmacists as 
well as with individual pharmacy offices. The agreements between the BCG and each of the pharmacist organizations were exclusively commercial, stating only the payment procedure. Other duties of the industry consortium (the three associations) included updating the list of pharmaceuticals that could be prescribed to NISSRP beneficiaries and developing a system to administer, manage, and periodically audit the services for providing ambulatory and cancer medicines.

Signing the agreement was a political decision made at the highest level of the NISSRP, without the participation of most of the NISSRP technical teams. The full text of the agreement was "classified" and not made available to the teams within the NISSRP that were technically the most medically qualified.

\section{MATERIAL AND METHODS}

\section{Database}

For our analysis, we included written prescriptions for each month of 1999 in a database using the Fox-Pro ${ }^{\mathrm{TM}}$ software (Microsoft Corporation, Redmond, Washington, United States of America). We compared those 1999 data with data that were available from the NISSRP Department of Economic Affairs for the period before the agreement was signed. For the 1999 data, we used data that the BCG had recorded for that year and given to the NISSRP. These data included the list of products available at the beginning of the agreement and during 1999. We subjected these data to a descriptive analysis of the prescriptions in terms of the number of prescriptions, the number of units included in the prescriptions, and the cost of the medicines.

\section{Indicators of nonrational prescribing}

To estimate the level of prescribing of nonrational products, we selected a sample of products in the Argentine market that were not registered in most developed countries and that were representative of the different therapeutic categories included in the Anatomical Therapeutic Chemical (ATC) classification system of the World Health Organization. The main criterion was that the selected products illustrate a breakdown of such principles of rational therapy as evidence of effectiveness or safety. With these products, we compared their consumption in 1996 with their consumption in 1999 within the NISSRP and also for the entire country (according to a market survey done by IMS HEALTH). The list of the selected products is presented in Table 1. Of the 13 products chosen, 8 of them were fixed associations, comprised of between two and seven different drugs, not supported by properly designed clinical trials; 3 were biologics lacking objective evidence of their effectiveness; and the remaining 2 were biologics containing what seems to be single molecules (ferritin and thyroglobulin). All 13 products had been available in Argentina for several years before the agreement was signed.

\section{Special applications}

Cumulative records of the expenditures corresponding to special applications for exceptional cases submitted by NISSRP beneficiaries for the provision of medicines were retrieved from the Medicines Department of the NISSRP. These records were for the periods of January 1997 through December 1997 and January 1999 through December 1999. In the cases where the applications were approved, the NISSRP covered the full cost of these medicines used in exceptional cases, that is, with the beneficiary receiving the product for free. The general criterion was that NISSRP had to provide the needed medicine when the beneficiary was unable to pay for it or because the beneficiary had a clinical condition that was not treatable with the products covered in the agreement with the pharmaceutical consortium. The procedure for special exceptions could be used by NISSRP beneficiaries to obtain a phar- maceutical when any one of nine conditions was met. The nine conditions were:

1) The product was one of a list of 54 medicines directly purchased by the NISSRP (including nutritional supplements, aldesleukin and some other biotechnological products, human immunoglobulins, and cyclosporine). The audit of these products was done by the NISSRP. The cost of these products was directly deducted from the amount fixed under the agreement, at the time of the monthly payment to the consortium.

2) The product was withdrawn from the agreement by a unilateral decision of the manufacturer. As with the first category, the cost of these products was directly deducted from the fixed amount at the time of the monthly payment to the consortium. The leading case was pyridostigmine $\left(\right.$ Mestinon $^{\mathrm{TM}}$ ), with only one provider in the market. Most of the cases involving these products are unresolved and still pending before a controversies commission that was established by the agreement to solve conflicts emerging while the agreement was in force.

3) Antineoplastic, AIDS, and transplantation medications not authorized by a special committee that was created by the BCG and that was composed of physicians and administrative staff. This committee received applications from pharmacy offices all over the country and had to give a written authorization for the product to be provided. If authorization was granted, the pharmacy office provided the product for free. If the authorization was not granted, the beneficiary could apply to the Department of Medicines to receive that product. If the Department of Medicines decided that the product was correctly prescribed, the NISSRP bought the product, and its price was deducted from the fixed payment amount, as in the first two categories. These products are not included among the drugs analyzed 
TABLE 1. Pharmaceutical products chosen to represent nonrational prescribing in study of an agreement in Argentina to transfer the financial risks with pharmaceutical benefits from the NISSRP to a consortium of pharmaceutical companies, 1996-1999a

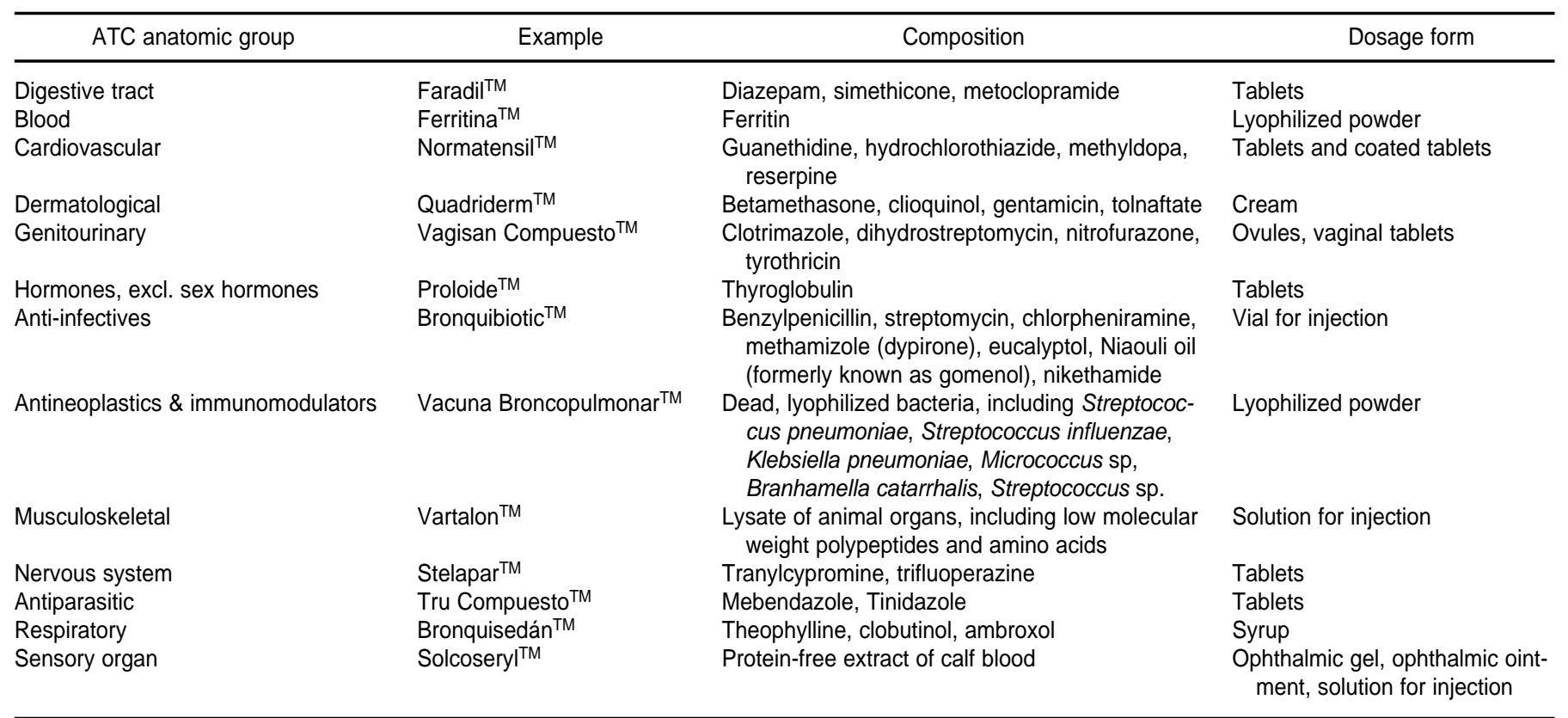

a Each example corresponds to one category of the Anatomical Therapeutic Chemical (ATC) classification system of the World Health Organization and was selected by consensus among the pharmacologists on the team who conducted this study.

in this article since no detailed consumption data for them were available at the time of analysis. This category was and still is a controversial point between the NISSRP and the pharmaceutical consortium, with the NISSRP saying that the deductions have been valid and the industry saying that the deductions have been too high.

4) New products, that is, ones that had not been included in the agreement because they were not being marketed when the agreement was signed.

5) Orphan drugs such as alglucerase.

6) Medicines for emergencies and natural catastrophes.

7) Some officinal preparations such as morphine syrup.

8) The income of the patient and his or her family was too low, with the expenditures for the medicines being greater than $10 \%$ of the total family income (only applied to relatives living with the patient).

9) Medicines to be used in case of travel to foreign countries; this category was very limited.
Among these nine conditions, the first three were paid for by the agreement. That is, under the agreement, their cost was included within the monthly US\$ 27.5 million. When the NISSRP itself purchased these products, an equal amount was deducted from the next payment to the consortium.

Values for exceptional applications (all categories) were not available for 1996 (January to December), so we used the earliest records available, which were ones for 1997 (which included five months before the agreement went into effect and seven months after that). According to NISSRP sources, these 1997 values were quite similar to the ones for 1996 (JCC, personal communication).

\section{Statistics}

Contingency tables (chi-square), Student's $t$ tests, and Mann-Whitney tests were used for the statistical analyses. All calculations were performed with the Stat-Primer software (5), with a level of $P<0.05$ being con- sidered significant. When applicable, results are presented below as mean \pm standard deviation of the mean.

\section{RESULTS}

\section{Products available to be prescribed}

One of the points agreed to by the NISSRP and the pharmaceutical-company associations was that the industry consortium would be responsible for updating the list of products to be accepted for prescription to NISSRP beneficiaries. Before the agreement had been signed, there had been a substantial delay by NISSRP in evaluating products for inclusion in its formulary. As a result of the consortium's review and the adding of some products and the dropping of others, the updated listing of 1999 had a net total of 1597 more products, which were organized into the same categories as the ones that the NISSRP had used before the agreement.

Drugs were dropped from the updated listing for two reasons. One of 
the reasons was a voluntary decision by the manufacturer. The second reason was that the price of the product had increased over the maximum price in the same therapeutic category. For example, if there were three brands of cotrimoxazole, ranked by price, none of them could raise its price over the maximum that had existed when the agreement came into effect. The two cheaper brands were allowed to rise to the price of the most-expensive one. However, if any of the three brands set a price over the original maximum, that brand was automatically excluded from the agreement.

As shown in Table 2, the distribution of the products accepted for prescription to NISSRP beneficiaries was quite similar in 1996 and 1999 in terms of their benefit coverage levels. Nevertheless, some additions were very atypical. For instance, amlodipine (which is mostly used for hypertension in the elderly) was included in the group of medicines with a benefit cov- erage level of $30 \%$, while most antihypertensives were in the $50 \%$ category, and the main products were in the $80 \%$ coverage-level group.

Many of the products that were added were new brands of the same drugs already in use before the agreement was signed. With just a few exceptions, products licensed after the agreement went into effect were not allowed to be prescribed. The few exceptions were drugs for a particularly severe or disabling disease (e.g., glaucoma), and this was only done very shortly after the agreement went into effect.

\section{Written prescriptions and units}

As shown in Table 3, the average number of prescriptions written during 1999 was slightly below 2.2 million monthly, corresponding to more than 3.5 million units a month, with a mean of 1.67 units per prescription. The total

TABLE 2. Distribution of pharmaceutical products accepted for prescribing to NISSRP beneficiaries in 1996 and 1999, before and after the signing of the agreement between the NISSRP and the pharmaceutical consortium, according to the percentage of benefit coverage for NISSRP beneficiaries

\begin{tabular}{|c|c|c|c|c|}
\hline & \multicolumn{4}{|c|}{ Number and $\%$ of products } \\
\hline & \multicolumn{2}{|c|}{1996} & \multicolumn{2}{|c|}{1999} \\
\hline & No. & $\%$ & No. & $\%$ \\
\hline \multicolumn{5}{|c|}{ Benefit coverage level } \\
\hline $100 \%$ & 114 & 2.3 & 161 & 2.5 \\
\hline $80 \%$ & 475 & 9.7 & 600 & 9.3 \\
\hline $50 \%$ & 1422 & 29.1 & 1860 & 28.7 \\
\hline $30 \%$ & 2872 & 58.8 & 3859 & 59.6 \\
\hline Total & 4883 & 100 & 6480 & 100 \\
\hline
\end{tabular}

TABLE 3. Average number of prescriptions (mean \pm standard deviation) for outpatient consumption among NISSRP beneficiaries in 1996 (before the agreement between the NISSRP and the pharmaceutical companies) and 1999

\begin{tabular}{ccc}
\hline Year & Average monthly prescriptions & Total annual units \\
\hline 1996 & $2303890 \pm 47351$ & 42479279 \\
1999 & $2194804 \pm 44137^{a}$ & 43870776 \\
\hline
\end{tabular}

a November 1999 was an atypical month, with the distribution of pharmaceuticals interrupted for a few days due to a decision by the pharmacist organizations. Excluding November, the mean monthly value for 1999 is $2259353 \pm 21262$ prescriptions.

numbers of units for the entire year were quite similar in 1996 and 1999.

\section{Cost}

Table 4 summarizes the distribution of costs corresponding to ambulatory products sold to NISSRP beneficiaries during 1999, distributed according to the coverage benefit level. Here, "cost" means the sum of the amount actually spent out of pocket by the beneficiaries plus the "nominal" amount for the NISSRP.

The percentage of expenditures in each coverage category was relatively constant over the year. Excluding November, an average of $40.04 \% \pm 0.26 \%$ (mean \pm standard deviation) of the expenditures corresponded to products for which patients had 30\% coverage (that is, their co-payment was $70 \%$ ), $21.04 \% \pm 0.18 \%$ to products with $50 \%$ coverage, $28.12 \% \pm 0.29 \%$ to products with $80 \%$ coverage, and $10.80 \% \pm 0.14 \%$ to products available for patients for free $(100 \%$ coverage, that is, no copayment). November 1999 was an atypical month, due to the transient interruption of drug dispensing in pharmacy offices as a result of a conflict that the pharmacist organizations had with the NISSRP.

Between 1996 and 1999 there was a large increase in total expenditures for the outpatient drugs provided through the NISSRP agreement with the pharmaceutical consortium. The amount that NISSRP beneficiaries spent out of pocket in those two respective years climbed from US\$ 336.13 million to US\$ 473.36 million, an increase of almost $41 \%$.

The nominal amount "spent" by the NISSRP itself rose to US\$ 601.11 million in 1999 (Table 5). That was an increase of some $60 \%$ over the US\$374.75 million that the NISSRP had actually spent in 1996. The nominal expenditures increased in all the coverage-level categories, but the relative size of the increase was greater for those drugs with higher benefit coverage levels. That increase for the NISSRP was only theoretical since the agreement specified the fixed monthly amount that the 
TABLE 4. Total nominal costs (US\$) for the NISSRP plus actual out-of-pocket costs for NISSRP beneficiaries for outpatient drug prescriptions in 1999

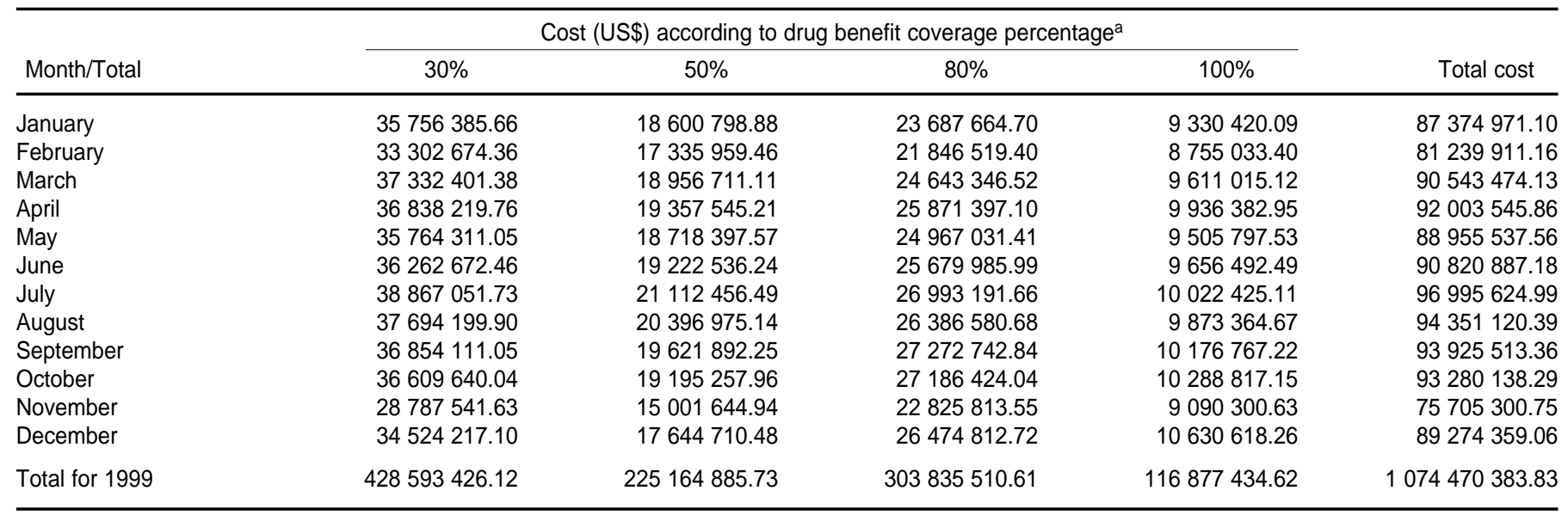

a The drug benefit coverage percentage is the part of the price for which the NISSRP is responsible.

NISSRP would have to pay to the pharmaceutical consortium.

While the increase for the NISSRP itself was a nominal one, the increase for the NISSRP beneficiaries was real. Per month, the average increase in outof-pocket costs was between US\$ 2.54 per beneficiary (using a 1999 population estimate of 4.50 million beneficiaries) and US\$ 3.41 per beneficiary (using a 2000 population calculation of 3.35 million beneficiaries). (For comparison, in both 1996 and 1999 most of the NISSRP beneficiaries had monthly incomes of less than US\$ 300.)

The mean price of ambulatory medicines (total cost of ambulatory medicines divided by the number of units sold) was US\$16.73 in 1996. The figure in 1999 was US\$24.49, an increase of some $46 \%$.

\section{Indicators of nonrational drug use}

Table 6 shows the distribution of the units sold for each of the products that we had selected as markers for nonrational prescribing, for both NISSRP beneficiaries and for the entire country. In the analysis for NISSRP beneficiaries, sales of some of the markers increased, but sales for others decreased, suggesting that the agreement had no one single, general effect on the prescribing of these products.
TABLE 5. Expenditures (US\$) for NISSRP outpatient medicines, according to the benefit coverage level, before and after putting into place the agreement with the pharmaceutical consortium: 1996 (real expenditures for January to December) vs. 1999 (nominal expenditures for January to December)

\begin{tabular}{lccc}
\hline & $\begin{array}{c}1996 \text { expenditures } \\
\text { (US\$) }\end{array}$ & $\begin{array}{c}1999 \text { expenditures } \\
\text { (US\$) }\end{array}$ & $\begin{array}{c}\text { Change from 1996 } \\
\text { to 1999 } \% \text { ) }\end{array}$ \\
\hline $\begin{array}{l}\text { Benefit coverage level } \\
100 \%\end{array}$ & 54951944.82 & 116877434.62 & 113 \\
$80 \%$ & 141737472.47 & 243068408.49 & 71 \\
$50 \%$ & 86093755.16 & 112582442.87 & 31 \\
$30 \%$ & 91970988.13 & 128578027.84 & 40 \\
Total/Overall & 374754102.58 & 601106313.82 & 60 \\
\hline
\end{tabular}

TABLE 6. Comparison of nonrational prescribing in the NISSRP and in Argentina overall in 1996 and 1999 in terms of number of units of selected products dispensed to NISSRP beneficiaries and distributed in the country overall

\begin{tabular}{|c|c|c|c|c|}
\hline \multirow[b]{2}{*}{ Example product } & \multicolumn{2}{|c|}{ NISSRP } & \multicolumn{2}{|c|}{ Argentina overalla } \\
\hline & 1996 & 1999 & 1996 & 1999 \\
\hline Faradil $^{\mathrm{TM}}$ & 21743 & 16822 & 118200 & 69000 \\
\hline Ferritina $^{\mathrm{TM}}$ & 4290 & 2192 & 17900 & 12600 \\
\hline Normatensil ${ }^{\mathrm{TM}}$ & 12685 & 9470 & 44300 & 28000 \\
\hline Quadriderm $^{\mathrm{TM}}$ & 39211 & 71842 & 989800 & 966200 \\
\hline Vagisan Compuesto ${ }^{\mathrm{TM}}$ & 7130 & 6997 & 203400 & 164600 \\
\hline Proloide $^{\mathrm{TM}}$ & 6191 & 18 & 56700 & $N D^{b}$ \\
\hline Bronquibiotic $^{\mathrm{TM}}$ & 19062 & 11583 & 80400 & 65200 \\
\hline Vacuna Broncopulmonar ${ }^{\mathrm{TM}}$ & 6611 & 5469 & 93700 & 62000 \\
\hline Vartalon ${ }^{\mathrm{TM}}$ & 34356 & 28466 & 120000 & 85400 \\
\hline Stelapar ${ }^{\mathrm{TM}}$ & 11633 & 11135 & 66200 & 48000 \\
\hline Tru Compuesto ${ }^{T M}$ & 1374 & 2656 & 59200 & 68900 \\
\hline Bronquisedán ${ }^{\mathrm{TM}}$ & 12527 & 28201 & 441600 & 598400 \\
\hline Solcoseryl ${ }^{\mathrm{TM}}$ & 4424 & 6278 & 19800 & 11300 \\
\hline
\end{tabular}

a Source of information for Argentina overall is market survey research done by IMS HEALTH, of Westport, Connecticut, United States of America.

${ }^{b} \mathrm{ND}=$ not determined in the IMS HEALTH survey in 1999. 
To test whether changes in the markers for nonrational prescribing were reflecting the impact of the agreement or were indicative of more general changes in the pattern in the use of medicines in Argentina, we compared the figures for the NISSRP with estimates made for the entire country, as calculated by the market survey done by IMS HEALTH. As shown in Table 6 , with 10 out of the 13 products analyzed, the pattern of change (either an increase or a decrease) in the NISSRP was the same as for Argentina overall.

\section{By-exception mechanism}

Since the list of drugs (not the brands) available for prescription was quite similar in 1996 and 1999, new medicines that the National Drug, Food, and Medical Technology Administration of Argentina (Administración Nacional de Medicamentos, Alimentos y Tecnología Médica, or ANMAT) had authorized since 1997 for general distribution in the country could not be prescribed regularly to NISSRP beneficiaries. We analyzed records of the accepted applications for the special exception procedures for patients to receive medicines for the years 1997 (January through December) and 1999 (January through December). (Since the information on rejected applications is not centralized, it is not possible to provide an accurate estimate of the proportion of applications that were accepted.) In 1997, the cumulative cost to NISSRP of the accepted applications had been US\$ 2895 088; the figure for 1999 was US\$ 10151 382, an increase of some $250 \%$. Most of this 1999 cost was paid by the NISSRP, since, as was mentioned earlier, the costs for only three of the nine special exception categories could be deducted from the fixed monthly amount set in the agreement.

\section{DISCUSSION}

To our knowledge, this is the first published report concerning utilizing an agreement such as this one in an effort to cope with pharmaceutical expenditures in a public health services system. Our data show that in the NISSRP case the transfer of the financial risks with the pharmaceutical benefits from the NISSRP to the pharmaceutical consortium neither reduced the nominal costs to the NISSRP itself nor improved the quality of the prescribing as shown by the pattern of nonrational prescribing. Indeed, the total cost for society increased markedly.

In this analysis, at least two variables are worth considering: the macroeconomic context in Argentina and the size of the NISSRP beneficiary population. In terms of macroeconomics, in the evaluated period of 1997 through 1999, Argentina's economy was quite stable, with an increase of less than $4 \%$ in the gross domestic product and a small decrease (deflation) in domestic prices. Thus, the increase in total NISSRP drug costs cannot be explained just in terms of inflationary pressures.

As to the NISSRP population, inaccuracies in the NISSRP database make it impossible to know what the actual number of beneficiaries was in 1996 or in 1999. This is a major limitation, which existed before the agreement was signed and was not corrected between 1997 and 1999. The lack of an accurate database hindered proper audit and facilitated fraudulent use of the drug benefit program. While real, this problem in the NISSRP still does not seem to explain the difference in expenditures that we found, since the number of written prescriptions and the numbers of units per prescription were almost the same in 1996 and 1999.

Though a direct comparison between written prescriptions for 1996 and 1999 is difficult, in approximately the same number of prescriptions, a relatively constant number of units was prescribed for a substantially higher cost. One possibility is that the mean price of the ambulatory pharmaceuticals for NISSRP beneficiaries increased. The increase probably reflected both a real price rise for some products and also a shift towards the consumption of more-expensive medicines, mainly among the ones more recently included in the list of brands covered by the agreement. However, the increase in the mean price of pharmaceuticals was a national phenomenon that was not limited to NISSRP beneficiaries. This indicates that there were additional factors operating, and not just a transfer of costs from the NISSRP itself to its beneficiaries.

From a theoretical point of view, the agreement had some advantages as well as pitfalls. One benefit was that it provided a precise figure for the expenditures to be assumed by the NISSRP to cover the pharmaceutical services for its beneficiaries. This improved the NISSRP budget calculations and allowed the NISSRP to make the best use of its economic resources. In addition, one possible-though not mandatory-outcome with the agreement was a reduction in the administrative and bureaucratic structures needed to manage the pharmaceutical benefits program. Indeed, some members of the NISSRP staff were recruited by the BCG, and most of the NISSRP structures remained in place, though with a reduced number of personnel. Another benefit was that the agreement required the pharmaceutical consortium to update the list of products that could be prescribed to NISSRP beneficiaries. Before the agreement, the NISSRP technical teams were supposed to do that, but their heavy workload had systematically hindered regular updating.

There were significant drawbacks with the agreement, from both a theoretical and a factual point of view. Probably the most important was the increase in the expenditures by beneficiaries. In addition, since the products that were available under the agreement were mostly ones that had appeared on the market before April 1997, demands for newer products were expected to increase over time, thus generating a future increase in expenditures. This was indeed the case, as shown by the increase in applications for special exceptions. The lack of updating of the pharmaceutical products that could be provided to NISSRP 
beneficiaries while the agreement was in place was not due exclusively to the agreement, since a renegotiation clause was included in it that provided a mechanism for updating the list of medicines covered as well as the fixed amount to be paid. Any change required the agreement of both the NISSRP and the pharmaceutical consortium. Nevertheless, due to differences in the views held by the parties to the agreement and probably also to the lack of NISSRP political will, no update was made in the two and a half years before this study, that is, from June 1997 to December 1999.

In addition, over the period we evaluated in our study, expenditures by the NISSRP for medicines under the procedure for special exceptions increased markedly. This involved an increase in the total expenditures for which the NISSRP was responsible since the NISSRP usually provided these medicines for special cases to its beneficiaries without charge (a 100\%coverage benefit).

In parallel with the implementation of the system defined in the agreement, the decision-making and management ability of the NISSRP decreased, which had the result of weakening its capacity to perform its duties. A last point is that the agreement had no impact on nonrational prescribing, which could make it easier for this undesirable pattern to become the accepted standard.

The "increase" in the NISSRP's expenditures from US\$ 374.75 million in 1996 to US\$ 610.11 million in 1999 (Table 5) was only theoretical, since the agreement fixed the amount to be paid by the NISSRP. This nominal increase can be seen as a discount made by the pharmaceutical companies as a consequence of the risk they assumed when they signed the agreement. In contrast to the NISSRP itself, the increase in the payments by the NISSRP beneficiaries had a real impact on their financial situation. This result in Argentina is consistent with the prediction of increased out-of-pocket expenses among elderly patients or people with a chronic condition if capitation rates were cut as a means of controlling expenditures in the Medicare program, which operates in the United States and serves aged and disabled persons (6).

With the agreement, there was a decrease in the decision-making and management ability of the NISSRP. While this was not included among the requirements of the agreement, there was no political decision to sustain the technical areas in the NISSRP needed to manage the contract. Before the agreement, the NISSRP had specific areas for informatics, billing control, and pharmaceutical audit as well as the Department of Medicines to determine which drugs were required for the beneficiaries, and the corresponding benefit level. These functions involved more than a hundred people working for the NISSRP all over the country; in addition, the NISSRP contracted for some third-party services. Those same third-party contractors and some of the more-qualified members of the NISSRP technical teams were later contracted by the pharmaceutical consortium through the BCG. Before the agreement, these structures were in place inside the NISSRP and performed their duties quite well, taking into account the heavy workload, the lack of appropriate computer hardware and software, and the bureaucratic procedures involved. Nevertheless, by signing the agreement, the NISSRP leadership seemed to indicate that they thought some other structure would work better. The need for the capacity to manage this kind of contract can be a critical issue in other areas of the public sector, such as social services provided by provinces and cities, where critical components of the operation are frequently outsourced.

Prescribing for the nonhospitalized elderly includes a significant proportion of inappropriate medication, though the exact magnitude is difficult to determine. An earlier study (7) reported that prescriptions for NISSRP beneficiaries included a noticeable number of medicines considered to be of low therapeutic value. Our results are consistent with that research, since we found several nonrational indicator products to be present in both years in roughly the same proportion. In a community-based study using data from the National Medical Expenditure Survey in the United States, roughly $25 \%$ of the prescribing was found to be inappropriate, according to objective criteria (8). It is not possible to directly compare our results with that study, for several reasons. First, the data that we have presented correspond to cumulative consumption by the entire NISSRP population over respective one-year periods, thus hindering a direct measure of the percentage of patients receiving each inappropriate drug. Second, the drugs analyzed for 1987 by Willcox et al. (8) involved a significant proportion of medicines not currently available in most parts of the world, including Argentina. Thirdly, and probably most importantly, the NISSRP population includes a large number of beneficiaries below the age of 65 years, including more than 750000 people (more than $20 \%$ of the total population) under the age of 60 .

It is important to keep in mind that the agreement involved only a part (though the largest) of the total expenditures that the NISSRP allocated to medicines. Besides drugs for nonhospitalized patients with common clinical conditions and cancer products that were covered under the agreement, drug benefits under the NISSRP regimen included drugs for AIDS patients (an estimated US\$ 1000 monthly per case, for approximately 700-800 patients), drugs for hemophiliacs (costing almost US\$ 5000000 annually for a total of some 400 patients), and hard-to-quantify expenses for various special programs. Among these special programs were a mother and child benefit, which provided free medicines to both pregnant women and to infants during the first year of life; influenza vaccinations; and coverage for drugs not included in the agreement, such as selective COX-2 inhibitors and other medicines licensed after May 1997. In addition, when NISSRP beneficiaries are hospitalized (whatever the medical reason), medicines required during hospitalization are included in the capitation rate paid by the NISSRP 
to the providers of the hospitalization service.

Besides risk contracts, other approaches can be used to control drug expenditures. For example, several attempts have been made to reduce coverage for nonrational medicines, but only limited evaluations of the results are available. One large study (9) involved a sample of almost 400000 people in the early 1980s in the United States who were enrolled in Medicaid, a program that uses federal and state funds to cover a wide range of inpatient and outpatient services for the poor and the permanently disabled. Excluding drugs categorized as lacking in scientific background resulted in an increase in costs rather than a decrease. Probably the only important benefit was an improvement in the quality of the prescribing and thus a reduction in the risks for the population and the costs associated with those risks. The authors suggested that interventions based on only one component of the prescribing chain are probably ineffective, due to compensatory effects such as a shift to other drugs available in the market.

A final point to analyze is how the agreement modified the competitive rules of the market for the pharmaceutical companies in Argentina. No published data address this point, but speculation is possible based on information frequently mentioned by unofficial sources within the pharmaceutical companies. The best-known rule is the system described as the "80:20 rule" for the distribution of the potential financial deficit among the pharmaceutical companies under the agreement. The calculation of the amount to be paid by the NISSRP to the pharmaceutical consortium was derived from the money that the NISSRP had paid for the pharmaceutical services it had provided to its beneficiaries before the agreement was signed. Since this amount was fixed, the increase in drug expenditures that occurred while the agreement was in force generated a financial deficit for the associations representing the pharmaceutical companies. This deficit had to be collaboratively supported by the BCG itself and by each pharmaceutical company according to the historical sales records for the products involved, divided into two categories. One category was old products, that is, ones that were present in the agreement from its initiation. The companies selling these old products had to contribute $20 \%$ of the deficit generated by the products, with the rest of the deficit being covered by the remaining companies. The second category was new products, that is, ones that were added after the agreement was signed. Companies selling these new products had to contribute $80 \%$ of their deficit cost to the group. The rationale for this asymmetrical distribution was to discourage unfair practices that could result in a shift in prescribing. The pharmaceutical companies ended up applying classical marketing practices, including using sales-representative visits, free drug samples, and gifts to doctors. Though any shift in prescribing or inclusion of new pharmaceuticals among those covered by the agreement was discouraged (and, indeed, no new companies were added to the agreement), the effect of the 80:20 rule was particularly important for drugs with a high benefit coverage level, especially if the products containing these drugs had been added to the agreement at some time after its initiation.

According to the IMS HEALTH market survey, the pharmaceutical services for the NISSRP are estimated to represent $30 \%$ of the overall pharmaceutical market in Argentina, but with significant differences among the pharmaceutical companies. In fact, the
NISSRP is recognized as the single largest buyer in the market. Since most pharmaceutical companies in Argentina do not offer shares publicly on the stock market, their financial statements are not public. This makes it difficult to directly estimate their profits, either overall or just from sales to the NISSRP.

Our analysis of prescriptions and costs indicates that the net result of the agreement between the NISSRP and the pharmaceutical consortium was an increase in the total costs for society. Our analysis also emphasizes the potential role of rational prescribing as a tool for coping with the increasing costs of the NISSRP health services.

An agreement such as this one in Argentina could be a useful tool. Nevertheless, it has definite limitations. First, it requires a political decision by decisionmakers to avoid the risk of an organization abandoning its responsibilities. The NISSRP is primarily a public organization with the aim of providing health services; health priorities have to define the allocation of resources, and not the reverse. Such an agreement also needs a strong technical structure, a close audit of drug prescribing (ideally, a real-time audit), an updating system for adding drugs, and a program for rational drug use.

Acknowledgements. We are indebted to E. Rodas, M.D., for transferring the original data to CDs; to P.M. Politi, M.D., Ph.D., for suggestions and discussion; and to Dr. Gabriela L. Magenta, Ms. Roxana Almirón, Ms. María de los Ángeles Olmos, and Mr. Martín $\mathrm{D}^{\prime}$ Ambrosio for assistance in different parts of the work. This research was performed as a by-contract support service provided by the School of Medicine of the University of Buenos Aires to the NISSRP between February and April 2000. 


\section{REFERENCES}

1. Berndt ER. The U.S. pharmaceutical industry: why major growth in times of cost containment? Health Aff 2001;20(2):100-114.

2. ISALUD. El mercado de los medicamentos en la Argentina. Estudios de la Economía Real 1999;13:104-128.

3. Argentina, Instituto Nacional de Estadística y Censos. Anuario estadístico de la República Argentina 2000. Buenos Aires: INDEC; 1999.

4. Tafani R. Reforma del sector salud en Argentina. Santiago de Chile: Comisión Económica Para América Latina y el Caribe
(CEPAL); 1997. (Serie Financiamiento del Desarrollo 53).

5. Glantz SA. Primer of biostatistics. New York: McGraw Hill; 1987.

6. Mueller C, Schur C, O'Connell J. Prescription drug spending: the impact of age and chronic disease status. Am J Pub Health 1997;87(10): 1626-1629.

7. Iñesta García A, Navarro I, Anzola Pérez E, Fefer E. Utilización de medicamentos por ancianos en la Argentina. Rev Esp Salud Publica 1995;69(3-4):315-327.
8. Willcox SM, Himmelstein DU, Woolhandler S Inappropriate drug prescribing for the community-dwelling elderly. JAMA 1994; 272(4):292296.

9. Soumerai SB, Ross-Degnan D, Gortmaker S, Avorn J. Withdrawing payment for nonscientific drug therapy. Intended and unexpected effects of a large-scale natural experiment. JAMA 1990;263(6):831-839.

Manuscript received 14 January 2002. Revised version accepted for publication on 4 September 2002.
RESUMEN

Transferencia de los riesgos económicos de conceder prestaciones por productos farmacéuticos de una gran empresa proveedora de asistencia sanitaria a un consorcio de compañías farmacéuticas
Objetivos. El Instituto Nacional de Servicios Sociales para Personas Jubiladas y Pensionadas (INSSPJP) es una agencia nacional que financia y provee servicios de salud en Argentina. Entre los servicios que provee figura la cobertura del costo de medicamentos adquiridos por la vía ambulatoria a más de 3,3 millones de beneficiarios, principalmente personas de edad avanzada o discapacitadas. En 1997, con el fin de ayudar a sufragar el aumento de los costos, el INSSPJP acordó transferir el riesgo de los costos de los medicamentos para pacientes ambulatorios y para el tratamiento del cáncer a un consorcio de compañías farmacéuticas a cambio de una cuota mensual fija. El objetivo del presente estudio es determinar qué impacto ha tenido esta medida en tres aspectos: 1) el nivel del gasto en los medicamentos abarcados por el acuerdo; 2) la tendencia a prescribir medicamentos de forma no racional para beneficiarios del INSSPJP y 3) la relación que muestra esta tendencia con las variables macroeconómicas y los patrones de prescripción en toda la Argentina.

Métodos. Comparamos el consumo de medicamentos por pacientes ambulatorios en 1999 con el consumo antes de la entrada en vigor del acuerdo.

Resultados. La cantidad que los beneficiarios del INSSPJP gastaron de su bolsillo aumentó de \$US 336,13 millones en 1996 a \$US 473,36 millones en 1999, aumento que equivale a casi 41\%. La cantidad nominal "gastada" por el INSSPJP en 1999 fue de \$US 601,11 millones, frente a la cantidad real gastada en 1996, que fue de \$US 374,75 millones. Esto representa un "aumento" de $60 \%$ (el aumento para el INSSPJP es solo teórico, ya que en el acuerdo se especificaba la cantidad mensual fija que esta entidad tendría que pagarle al consorcio de compañías farmacéuticas). A diferencia del aumento del gasto real que afectó a los beneficiarios del INSSPJP, la economía argentina permaneció estable durante el período estudiado, cuando el índice de precios al consumidor hasta se redujo en $0,8 \%$. Hallamos un uso frecuente de medicamentos de forma irracional en el sistema del INSSPJP tanto en 1996 como en 1999, dato que apunta a la presencia de un problema importante.

Conclusiones. Un acuerdo con compañías farmacéuticas como el aquí descrito podría aportar un elemento de pronosticabilidad para instituciones tales como el INSSPJP. No obstante, un acuerdo de este tipo bien podría aumentar la carga económica de los beneficiarios de las prestaciones de salud, sin que mejoren en modo alguno los servicios que reciben. Los acuerdos de este tipo exigen que haya complejos mecanismos de control, seguimiento y actualización, y al mismo tiempo acarrean el peligro de que la prescripción irracional de medicamentos se convierta en práctica habitual. Aunque su factibilidad no es de dudar, los mecanismos que exigen estos acuerdos son muy difíciles de implantar y su puesta en marcha plantea la necesidad de medidas adicionales por parte de instituciones como el INSSPJP. 